\title{
RELAÇÃO SER HUMANO-NATUREZA: REFLEXÃO E DESAFIO DA EDUCAÇÃO FÍSICA ${ }^{1}$
}

\author{
Priscilla Pinto Costa da Silva \\ Universidade de Pernambuco, Recife, Pernambuco, Brasil \\ Emília Amélia Pinto Costa da Silva \\ Universidade de Pernambuco, Recife, Pernambuco, Brasil
}

Andrea Maria Pires Azevedo

Universidade de Pernambuco, Recife, Pernambuco, Brasil

Leonardo Oliveira dos Santos

Universidade de Pernambuco, Recife, Pernambuco, Brasil

Clara Maria Silvestre Monteiro de Freitas

Universidade de Pernambuco, Recife, Pernambuco, Brasil

\section{Iraquitan Oliveira Caminha}

Universidade Federal da Paraíba, João Pessoa, Paraíba, Brasil

\section{Resumo}

O ensaio conduz à questão norteadora: em que medida a educação física pode contribuir para ressignificar a relação entre o ser humano-natureza? O objetivo foi discutir como a educação física pode ressignificar a relação ser humano-natureza, em torno do pensar complexo e das práticas corporais na natureza. Como principais considerações, observou-se que a educação física se aproxima com o pensamento complexo, no que diz respeito à relação ser humano-natureza, introduzindo-o a uma visão de elemento do cosmo. Neste sentido, a educação física tem como objeto as práticas corporais na natureza, permitindo reencontrar e integrar o ser humano como elemento do cosmo, capaz de valorizar o respeito a si mesmo, ao próximo e a natureza.

Palavras-chave: Natureza - Educação física - Educação

\section{Introdução}

Densar as práticas corporais na natureza, como fator de reaproxima-
ção do ser humano com a natureza, exige uma ressignificação da

1-Este estudo contou com o apoio financeiro da Coordenação de Aperfeiçoamento do Pessoal de Nível Superior - CAPES. 
educação física, enquanto prática esportiva. Essa prática transcende questões técnico-esportivas e ressignifica, do ponto de vista ecológico, a cultura corporal esportiva.

O ser humano citadino vivencia um distanciamento de sua vida com relação à natureza (COSTA, 2000). Ele estabelece um dualismo entre ele e a natureza, no qual Inácio et. al. (2005a, p.83-84) buscam apresentar uma "compreensão mais ampliada de Natureza a qual abarca todos os seres vivos, o meio ambiente físico, o cosmo e as dimensões intangíveis". No entanto, Morin e Kern (2000); Morin (2005) destacam que é preciso compreender a natureza e a sociedade como unidade, pois ela não pode ser idealizada como exterior à sociedade, por estabelecer uma relação histórica. Os autores adverte que os seres humanos, por consequência da humanidade, da cultura, do espírito e consciência, tornam-se estranhos ao cosmo. Desta forma, Ott (2009), aponta que o ser humano ofereceu pouca ou nenhuma atenção ao meio ambiente e a natureza, e agora se preocupa com as questões ambientais, em torno da política e da ética.

O ser humano, em uma perspectiva complexa, deve ser pensado em constante relação com a natureza, concebida como uma construção social, que perpassa por situações históricas, a qual envolve a sociedade contemporânea, o processo civilizador e suas relações. Pelo viés do progresso da ciência, cabe considerar que a trajetória da existência humana estabelece uma dicotomia entre o ser humano e natureza, isto porque na construção da ciência moderna, conforme Navarro (2004, p. 31 ), o ser humano se encontra fora da natureza, assim como a natureza se encontra fora do ser humano, destarte o "homem e natureza fragmentados nos processos cognitivos de interpretação e representação dos fenômenos do mundo".

Contrário a uma posição fragmentada do ser humano em relação à natureza, Morin (2005, p. 22) compreende que o ser humano apresenta um sentido múltiplo, podendo ser individual, social e biológico. No entanto, "a dissociação dos termos indivíduo/sociedade/espécie rompe com a sua relação permanente e simultânea". Assim, Inácio et al. (2005a) indicam que por meio de práticas corporais na natureza, os seres humanos podem se ver como elemento universal. Neste sentido, a relação ser humano-natureza pode ser articulada por meio da educação física e suas práticas corporais como apontam Silva e Freitas (2010); Betrán e Betrán (2006); Schwartz (2006) e Inácio et al. (2005a; 2005b). Os estudos desenvolvidos pelos referidos autores indicam que 
as práticas corporais na natureza permitem uma aproximação na relação ser humano-natureza, contudo, a educação física necessita repensar a unidade do ser humano, como elemento do cosmo.

As reflexões dos autores citados incidem nas múltiplas dimensões do pensamento complexo, como elemento que contribui na relação de repensar a unidade, uma vez que a complexidade se encontra no conhecimento, na vida cotidiana, e está inserida no conhecimento científico, entorno da ação e da ética (MORIN, MOIGNE, 2000). Pensar a complexidade requer transformar as ações do ser humano em relação à natureza, compartilhando na organização das atividades humanas. Desta forma, questiona-se: em que medida a educação física pode contribuir para ressignificar a relação entre o ser humano-natureza? Assim, o presente estudo discutiu como a educação física pode ressignificar a relação ser humano-natureza, em torno do pensar complexo e das práticas corporais na natureza.

\section{Educação Física: algumas aproximações com o pensamento com- plexo}

Pensar nas dimensões do pensamento complexo, à luz da relação ser humano-natureza, exige uma discussão a partir de duas perspectivas. A primeira traz o ser humano como elemento incluso a natureza, assim este "paradigma faz do homem um ser natural", tornando-o elemento do cosmo (MORIN, 2003, p. 25). O outro paradigma proposto pelo autor, diz respeito à separação entre estes termos, excluindo, desta forma, a ideia do ser humano na natureza, criando uma dualidade a partir de duas esferas diferentes. Estes dois paradigmas, expostos por Morin (2005), apontam para o paradigma complexo, posicionando-se o paradoxo do uno e do múltiplo. Portanto, os paradigmas impedem conceber a unidualidade: natureza $\leftrightarrow$ cultura, cerebral $\leftrightarrow$ psíquica. Os avanços do conhecimento científico, todavia, pouco colaboraram com o conhecimento dos processos de subjetivação, fruto da relação ser humano-natureza. Este, autor aponta que a realidade impede que se conceba a conjunção e a separação entre o ser humano e a natureza, conforme o paradigma complexo à luz da implicação/distinção/conjunção.

Neste sentido dual, é importante destacar o paradigma cartesiano formulado por Descartes, caracterizado por uma visão mecanicista, focando uma radical distinção entre o extenso e o cognitivo, concedendo 
a dicotomia entre ser humano e a natureza. Nessa direção, o sentido reducional, da ciência ocidental, apostou no que "reduz o conhecimento do conjunto ao conhecimento das partes que o constituem, pensando que podíamos conhecer o todo se conhecêssemos as partes" (MORIN, 2000, p. 3). Esse paradigma cartesiano resulta nessa dupla visão do mundo, separando o corpo e mente, definindo o corpo com base na ideia reducionista de matéria, e a mente no idealismo transcendente (GONÇALVES, 1994). A dissociação permite organizar o conhecimento, a partir da esfera física e mental, não havendo uma interligação. Para tanto, Morin (2000) ressalta que o todo precisa está inserido no uno e o uno está no todo. Assim o princípio deste paradigma pode melhor contribuir para a prática da educação física, no tocante à relação ser humano-natureza.

Como o autor destaca, o sistema educacional privilegia a separação, em vez de valorizar a ligação entre as partes. Desta forma, apontando que o conhecimento precisa ser pensado de forma complexa. Todavia, a tendência da ciência é separar para melhor entender. Parafraseando um exemplo proposto, "se quisermos conhecer o espírito humano, podemos fazê-lo através das ciências humanas, como a psicologia, mas o outro aspecto do espírito humano, o cérebro, órgão biológico, será estudado pela biologia" (MORIN, 2000, p. 2).

Seguindo as ideias de Morin, o homem vive uma realidade multidimensional e simultânea, em que a economia, a política, a psicologia, a sociologia, a mitologia são vivenciadas, mas, por outro lado, são estudadas isoladamente, e não relacionando umas as outras. Portanto, o isolamento torna o homem mais lúcido de uma parte de um contexto, mas se distancia da ideia e sua relação com o todo. Em algumas situações, o princípio da especialização do conhecimento contribui para esmiuçar um objeto de estudo, no entanto, esse estudo é limitado, pois não se deve desconsiderar o contexto desse objeto situado. De forma similar, não se deve pensar e compreender o ser humano apenas por um âmbito, visto que para compreendê-lo é preciso vê-lo no todo.

Confrontando este paradigma, torna imperativa uma visão integrada, a partir do paradigma sistêmico, permitindo uma compreensão da organização e dos sistemas que produzem fundamentos para o mundo, como aponta Morin (2000) no sentido de superar o paradigma mecanicista. Nesse cenário, faz-se necessária a reforma do pensamento para produzir um conhecimento complexo, como exigência de um paradigma sistêmico capaz de compreender o todo que constitui as partes, 
pois somente um sistema complexo estabelece uma aliança sistêmica (MORIN, 1999).

Sob esta ótica, Morin (1991, p. 93), assinalou que "na história ocidental houve o domínio de um paradigma da simplificação. O paradigma da complexidade surgirá do conjunto de novas reflexões que vão conciliar-se e juntar-se". Morin (2001) aponta a reforma de um pensamento capaz de conceber o conjunto favorecendo a responsabilidade e a cidadania de ordem ética e cívica. Desta forma, refletir uma reforma de pensamento na educação física permite contribuir na comunicação em um sentido metadisciplinar, desenvolvendo das partes ao todo, e concomitante do todo às partes (MORIN, 2000).

A educação física, pensada de forma sistêmica, a partir da complexidade, busca compreender a emergência no processo de formação, quanto ao conhecimento corpo/mente, nos âmbitos individual e social do ser humano. Então, é interessante trazer estudos da corporeidade, por manter uma relação conjunta entre as práticas corporais, a consciência, a comunicação e interação nas relações do eu, com a sociedade e com a natureza, como enfatizam os estudos de Monteiro (2006) e Loureiro (2005). Compreender a corporeidade, a partir do pensamento complexo, favorece à educação física a pensar a relação ser humanonatureza, envolvendo as dimensões existentes nestas práticas.

Assim, o pensar complexo conduz a educação física à construção de um pensamento de forma global e complexa, como apontam Ramos e Neves (2008). Nesta direção, a educação física dirige para a transdisciplinaridade, como meio de estabelecer conhecimentos práticos e específicos, articulando com conhecimentos próximos a construir novas formas de pensar gerando a desordem, mas, que estabelecem uma ligação com elementos complementares e antagôni$\cos$.

\section{Práticas corporais na natureza e a relação ser humano-natureza}

As práticas corporais na natureza podem colaborar para uma reaproximação do ser humano como elemento da própria natureza, no qual Morin, (2000) destaca que foi comprometida por meio de uma educação desfragmentada, que concebe as formas isoladas, distanciando do cosmo. $\mathrm{O}$ autor aponta que criar condições em que a humanidade concebe a uma sociedade/comunidade das nações, consiste na reforma das relações entre os homens, com si mesmo e com o próxi- 
mo, despertando para a relação entre seres humanos e a sociedade e discorre no conhecimento do ser humano e natureza (MORIN, 2000). A partir desta lógica, o pensamento complexo, atribuído às práticas corporais na natureza, permite aproximar e integrar o ser humano na natureza por meio de um sistema educacional transdisciplinar, que a educação física pode proporcionar visando uma quebra da dicotomia e reconstruindo a unidade ser humano-natureza.

Estudo realizados por Inácio et al. (2005a; 2005b); Betrán e Betrán (2006); Marinho (2008; 2009), Bruhns (2009); Anjos (2009); Silva e Freitas (2010) trazem as práticas corporais na natureza como meio de retomar vivências e experiências do ser humano com a natureza, as quais foram distanciada pela evolução da cultura. Neste contexto, Inácio et al. (2005); Inácio (2006); Monteiro (2006) e Betrán e Betrán (2006) apontam que uma estratégia educacional traz um sentido de alteridade aos sujeitos que praticam no que resulta no sentimento de sensibilização com o outro, com a natureza, despertando para novas formas de pensar e agir no cenário do meio ambiente.

Os meios midiáticos e as grandes indústrias têm trabalhado para a conscientização ambiental, com o objetivo de a humanidade cuidar melhor do planeta. Assim, as práticas corporais na natureza podem reverter hábitos que causam danos a ela, além de resgatar e recuperar a relação ser humano-natureza (BRANDY, 2006). Quanto a este aspecto, Bruhns (2009) lembra que não é apenas uma vivência que vai proporcionar mudanças aos praticantes; o respeito à natureza por meio dessas práticas se dá pelas experiências vivenciadas aos poucos, despertando os sujeitos para a problemática ambiental.

O naturalista americano Cornell (1996; 1997) desenvolveu o Aprendizado Sequencial, trazendo elementos teórico-metodológicos, que consistem em despertar curiosidades sobre a natureza por meio de quatro estágios: despertar o entusiasmo, concentrar a atenção, dirigir a experiência e compartilhar a inspiração. Estes estágios buscam despertar para uma sensibilização ambiental, a partir de atividades lúdicas para crianças. Esta estratégia educacional vem sendo utilizada em algumas pesquisas desenvolvidas no Brasil, com diferentes públicos. Como exemplo, os atores sociais com necessidades especiais, desenvolvido por Munster (2004). O estudo apontou que os praticantes revelaram sensibilização quanto aos problemas ambientais, além de maior aproximação entre os atores sociais e a natureza objeto das investigações. Um outro olhar conduziu para uma análise pedagógica, 
em que foi possível considerar às estratégias educacionais que despertaram, nos sujeitos, situações muitas vezes despercebidas no cotidiano citadino. Neste aspecto, as práticas corporais na natureza podem conduzir a valorização das experiências sensoriais que desenvolvem os sentidos, por meio da percepção de diferentes sons proporcionados por animais e o vento nas árvores, os aromas da terra e das flores, as texturas das árvores, além dos aspectos visuais quanto às cores e formas dos elementos naturais (CORNELL, 1996; 1997). As práticas corporais na natureza, segundo a perspectiva complexa, despertam nos sujeitos o repensar de sua relação consigo, o outro e a natureza, o que permite desenvolver novas formas de pensar a natureza, como parte de si. Então, o cuidar do eu pode ser introduzido pelo cuidar da natureza, construindo com os outros elementos reflexivos da própria existência no cosmo, apresentando aos praticantes a possibilidade de se ressignificar a natureza.

Com base em um paradigma sistêmico, as estratégias educacionais adotadas podem considerar o ser humano como ser integrado à natureza. Deste modo, os estudos de Morin e Kern (2000) apontam que o desenvolvimento do ser humano deve partir da perspectiva das potencialidades psíquicas, espirituais, sociais, culturais e éticas. Assim, as práticas corporais na natureza podem contribuir para o desenvolvimento humano integrado à natureza, visto que estas despertam para uma nova forma de pensá-la. Nesta perspectiva, os estudos desenvolvidos, no âmbito da educação física, tratam as práticas corporais na natureza como meio para ressignificar a relação ser humano-natureza, com foco na aprendizagem transdisciplinar. Considera-se a natureza como cenário para promover educação, a partir das intervenções da educação física permitindo um diálogo entre o ser humano e a natureza por meio das sensações proporcionadas pelas práticas, capazes de harmonizar experiências significativas como apontam Tahara e Carnicelli Filho (2008); Tahara, Dias e Schwartz (2006).

Ainda no contexto, as intervenções nas práticas corporais na natureza incidem as mudanças axiológicas, referentes aos novos conceitos e estilos de vida como apresentam o estudo de Schwartz (2006), em que os valores são desenvolvidos nas relações humanas e concepção de si. Deste modo, contribuir com a integração do ser humano com a natureza requer uma interação entre os órgãos dos sentidos, percepção e ação (SCHWARTZ, 2006; LOUREIRO, 2005). É interessante destacar, ainda, que as mudanças provocadas por meio da sensibilização, a 
partir de práticas corporais na natureza, podem romper a dicotomia do espaço urbano-natureza, campo-cidade, por trazer novas concepções adquiridas na natureza para o espaço citadino, no sentido de conservação do ambiente que se vive, e de possibilitar o desenvolvimento para uma conduta ética frente à natureza e aos seres humanos (INÁCIO et al., 2005a). O estudo de Silva (2008), assinala sobre os praticantes que retornam a cidade experimentam e percebem outros elementos que são sensíveis de sentir e ouvir a natureza do que no ambiente citadino, mas que são encontrados, como por exemplo, os sons dos animais, no entanto, na maioria das vezes na cidade não são percebidos.

Com base nesses aspectos, é importante ressaltar que a natureza está disseminada a partir das condições de vida e dos elementos naturais existentes, sejam eles em um espaço natural, ou no espaço citadino, mas, que engloba a relação de um todo inserido no cosmo, quebrando desta forma a dicotomia do espaço da cidade e do espaço da natureza. Lembrando do pensamento complexo de Morin, propõe-se uma nova forma de pensar e romper barreiras permitindo uma relação harmoniosa entre ser humano e natureza, seja no espaço citadino, ou no espaço natural, reconstruindo a unidade ser humano-natureza.

\section{Considerações Finais}

O desafio, em que essa discussão evidencia, consiste em pensar a educação física na perspectiva da relação ser humano-natureza, à luz do pensamento complexo, significa expandir o conhecimento de um contexto. Cabe destacar o papel da comunicação, entre o meio social e físico, que permite ver o ser humano como elemento do cosmo, fortalecendo a relação ser humano-natureza. Neste sentido, o pensamento complexo reintegra o ser humano entre os seres naturais, vendo estes como elementos intrínsecos da natureza, rompendo fronteiras comportamentais.

A análise permite inferir que a complexidade do ser humano está interligada nas formas de como se relaciona com o mundo. Portanto, é desafio, sobretudo, para a educação física, apresentar vivências sensibilizadoras em que recai o despertar do ser humano como elemento inserido no cosmo. Assim, as práticas corporais na natureza estão sendo aplicadas também pela educação física, na tentativa de resgatar o fenômeno de interação ser humano-natureza.

A educação física precisa repensar suas estratégias educacionais, 
com foco no ser humano, enquanto elemento do cosmo, considerando as mais diversas formas dialógicas das ações nos universos físico, biológico e humano, a partir do pensamento complexo. Em síntese, a educação física pode contribuir na relação ser humano-natureza, por meio da realização de práticas corporais na natureza no sentido de enfatizar a formação do ser humano enquanto ser integrado ao cosmo, capaz de valorizar o respeito a si mesmo, ao outro e a natureza. Entretanto, cabe, não somente tomar a natureza como objeto de estudo, mas, sobretudo, como lugar de vivências corporais.

\title{
Relation human-nature: reflection and challenge of physical education
}

\begin{abstract}
The essay leads to focus the question: what measure the physical education can contribute to reframe the relationship between human and nature? The aim was to discuss how physical education can reframe the relationship between human and nature around the complex thinking and body practices in the nature. Observed that physical education approaches with complex thinking regarding the relationship between human and nature, introducing to a vision element of the cosmos. Therefore, physical education has as object the body practices in the nature, lets recover and integrate the human as part of the cosmos, capable of enhancing respect for self, neighbor and the nature.
\end{abstract}

Keywords: Nature - Physical Education - Education

\section{Relación ser humano-naturaleza: reflexión y reto de la educación física}

\section{Resumen}

El texto lleva a la pregunta de investigación: en que medida la educación física puede ayudar a replantear la relación entre seres humanos-naturaleza? El objetivo fue discutir cómo la educación física puede replantear la relación seres humanos-naturaleza alrededor de el pensamiento complejo y la práctica corporal en la naturaleza. Como las principales consideraciones, se observó que la educación física enfoques con el pensamiento complejo en lo que respecta a la relación ser humano-naturaleza, presentarle una vista del elemento del cosmos. Así, la educación física, tiene por objeto las prácticas corporales en la naturaleza, lo que le permite cumplir e integrar el humano como elemento del cosmos, capaz de mejorar el respeto al prójimo uno mismo, y la naturaleza.

Palabras clave: Naturaleza - Education Física - Educacíon

\section{Referências}

ANJOS, J.L. Lazer e meio ambiente: percepções de escolares e de coletores de caranguejo de Barra Nova/ES. Revista Movimento, Porto 
Alegre, v. 15, n. 3, p. 315-332, 2009. Disponível em: < http://seer.ufrgs.br/Movimento/article/viewArticle/2215/5840>. Acesso em: 22 mai. 2010.

BETRÁN, J.O.; BETRÁN, A.O. Proposta pedagógica paras as Atividades Físicas de Aventura na Natureza (Afan) na educação física do ensino médio. In: MARINHO, A.; BRUHNS, H.T. Viagens, Lazer e Esporte: o espaço da natureza. Barueri: Manole, 2006.

BRADY, E. The Aesthetics of Agricultural Landscapes and the Relationship Between Humans and Nature. Ethics, Place \& Enrironment: A Journal of Philosophy \& Geograpy, v. 9, n. 1, p. 1-19, 2006. Disponível em $<$ http://www.informaworld.com/smpp/content $\sim \mathrm{db}=$ all $\sim$ content $=\mathrm{a} 743764668 \sim$ frm $=$ titlelink$?$ words $=$ relationship,nature $>$ Acesso em: 10 ago. 2010.

BRUHNS, H.T. A busca pela natureza: turismo e aventura. Barueri: Manole, 2009.

CORNELL, J. Brincar e Aprender com a Natureza: um guia sobre a natureza para pais e professores. São Paulo, SENAC/Melhoramentos, 1996.

CORNELL, J. A Alegria de Aprender com a Natureza: atividades ao ar livre para todas as idades. São Paulo, SENAC/Melhoramentos, 1997.

COSTA, V.L. M. Esportes de Aventura e Risco na Montanha. São Paulo: Manole, 2000.

GONÇALVES, M.A.S. Sentir, pensar, agir: corporeidade e educação. Campinas: Papirus, 1994.

INÁCIO, H. L. D. Lazer, Educação Física e Meio Ambiente: Uma aventura em construção. Pensar a Prática, v. 9, n. 1, p. 45-63, 2006. Disponível em: < http://www.revistas.ufg.br/index.php/fef/article/view/121/116> Acesso em? 20 out. 2010.

INÁCIO, H.L.D. et al. Travessuras e Artes na Natureza: movimentos de uma sinfonia. In: SILVA, A. M. e DAMIANI, I.R. (org.) Práticas Corporais: Experiências em Educação Física para a outra Formação Humana. v. 2, Florianópolis, Nauemblu Ciência \& Arte, 2005a. 
INÁCIO, H.L.D. et al. Bastidores das práticas de aventura na natureza. In: SILVA, A. M. e DAMIANI, I.R. (org.) Práticas Corporais: Experiências em Educação Física para a outra Formação Humana. v. 3, Florianópolis, Nauemblu Ciência \& Arte, 2005b.

LOUREIRO, C.F.B. Complexidade e dialética: contribuições à práxis política e emancipatória em educação ambiental. Revista Educação e Sociedade, Campinas, v. 26, n. 93, p. 1473-1494, set./dez. 2005.

MARINHO, A. Lazer, aventura e ficção: possibilidades para refletir sobre atividades realizadas na natureza. Motriz. v. 15, n. 1, Rio Claro, p. 01-12, 2009. Disponível em: <http://www.periodicos.rc.biblioteca.unesp.br/index.php/motriz/article/view/1969/1916> Acesso em: 15 mai. 2010.

MARINHO, A. Lazer, Aventura e Risco: reflexões sobre atividades realizadas na natureza. Revista Movimento. Porto Alegre, v. 14, n. 02, p. 181-206, 2008. Disponível em: <http://seer.ufrgs.br/Movimento/article/viewArticle/5756> Acesso em: 15 mai. 2010.

MONTEIRO, S.V. Lazer, natureza e amizade: formas de subjetivação na modernidade tardia. In: MARINHO, A.; BRUHNS, H.T. Viagens, Lazer e Esporte: o espaço da natureza. Barueri: Manole, 2006.

MORIN, E. Introdução ao pensamento Complexo. Lisboa: Instituto Piaget, 1991.

MORIN, E. Por uma reforma do pensamento. In: PENA-VEJA, A.; NASCIMENTO, E.P. (Org.) O pensar complexo: Edgar Morin e a crise da modernidade. Rio de Janeiro: Garamond, 1999. p. 21-34.

MORIN, E. Da necessidade de um pensamento complexo. In: MARTINS, F.M.; SILVA, J.M. (org.). Para navegar no século XXI. Porto Alegre: Sulina/Edipucrs, 2000.

MORIN, E.; KERN, A.B. Terra-Pátria. Tradução: Paulo Azevedo Neves da Silva. Porto Alegre: Sulina, 2000.

MORIN, E.; MOIGNE, J.L. A inteligência da complexidade. Tradução: Nurimar Maria Falci. São Paulo: Peirópolis, 2000. 
MORIN, E. A cabeça bem-feita: repensar a reforma, reformar o pensamento. Tradução: Eloá Jscobina. 4ed. Rio de Janeiro: Bertrand Brasil, 2001.

MORIN, E. Os sete saberes à educação do futuro. Tradução: Catarina Eleonora F. da Silva e Jeanne Sawaya. $8^{\circ}$ ed. São Paulo: Cortez; Brasília: UNESCO, 2003.

MORIN, E. O Método 1: a natureza da natureza. Tradução: Ilana Heineberg. $2^{\circ}$ ed. Porto Alegre: Sulina, 2005.

MUNSTER, M.A.V. Esportes na Natureza e Deficiente visual: Uma Abordagem Pedagógica. 2004. Tese (Doutorado em Educação Física) - Faculdade de Educação Física. Universidade Estadual de Campinas. Campinas, 2004.

NAVARRO, M.B.M.A. Homem e natureza: cognição e vida como elos indissociáveis. Ciência \& Cognição, v. 1, p. 29-33, 2004. Disponível em: $\quad<\mathrm{http}: / /$ www.cienciasecognicao.com.br/pdf/v01/cec_vol_1_m3142.pdf $>$ Acesso em 20 mai. 2010.

OTT, P. World and Earth: Hannah Arendt and the Human Relationshhip to Nature. Ethics, Place \& Environment: A Journal of Philosophy \& Geography., v. 12, n. 1, 2009, p. 1-16.

RAMOS, A. M.; NEVES, R. L. R. A inicialização Esportiva e a Especialização Precoce à Luz da Teoria da Complexidade - Notas Introdutórias. Pensar a Prática, v. 11, n. 1, p. 1-8, 2008. Disponível em? < http://www.revistas.ufg.br/index.php/fef/article/viewArticle/1786/3339> Acesso em? 04 out. 2010.

SILVA, F.W. Corpo e Natureza: perspectivas para uma educação do corpomundo. Dissertação de mestrado - Departamento de Educação Física, Universidade Federal de Santa Catarina, Florianópolis, 2008.

SILVA, P.P.C.; FREITAS, C.M.S.M. Emoções e riscos nas práticas na natureza: uma revisão sistemática. Motriz, v. 16, n. 1, p. 221-230, 2010. Disponível em: <http://www.periodicos.rc.biblioteca.unesp.br/index.php/motriz/article/viewFile/2618/2890> Acesso em 12 set. 2010. 
SCHWARTZ, G.M.A aventura no âmbito do lazer: as AFAN em foco. In: SCHWARTZ G.M. (org.). Aventuras na natureza: consolidando significados. Jundiaí: Fontoura, 2006, p. 23-31.

TAHARA, A.K.; CARNICELlI FILHO, S. Atividades físicas de aventura na natureza (AFAN) e academias de ginástica: motivos de aderência e benefícios advindos da prática. Revista Movimento, v. 15, n. 3, 2009, p. 187-208. Disponível em <http://seer.ufrgs.br/Movimento/article/viewArticle/4917/5834> Acesso em 28 mai. 2010.

TAHARA, A. K.; DIAS, V. K.; SCHWARTZ, G. M. A Aventura e o Lazer Como Coadjuvantes do Processo de Educação Ambiental. Pensar a Prática, v. 9, n. 1, 2006, p. 1-12. Disponível em < http://www.revistas.ufg.br/index.php/fef/article/view/121/116> Acesso em: 20 out. 2010.

Recebido em: 08/11/2010

Revisado em: 12/11/2010

Aprovado em: 31/09/2011

\section{Endereço para correspondência}

clarasilvestre@uol.com.br

Clara Maria Silvestre Monteiro de Freitas

Universidade de Pernambuco.

Rua Arnóbio Marques, 310 - Campus Universitário

Santo Amaro

50100-130 - Recife, PE - Brasil 